\title{
Exenatide: An incretin-mimetic agent
}

Diabetes mellitus is a chronic metabolic disorder, the worldwide point prevalence of which is estimated to be $8.6 \%$ in subjects more than 20 years and $20.1 \%$ in subjects more than 65 years of age. ${ }^{[1,2]}$ The major pathophysiological feature is either reduced insulin secretion or reduced insulin sensitivity resulting in hyperglycemia. Diabetes mellitus is of two major types namely type 1 and type 2 . Type- 1 has two subtypes namely $1 \mathrm{~A}$ and $1 \mathrm{~B}$. Type-1A is characterized by insulin deficiency due to autoimmune B-cell destruction. Type-1B is idiopathic, in which there is insulin deficiency without immunological markers of autoimmune destruction. Type-2 demonstrates varying degree of insulin resistance, impaired insulin secretion and increased glucose production due to genetic and metabolic defects in insulin action. ${ }^{[2]}$

In addition to dietary and/or lifestyle modifications, the treatment option for type-1 diabetes is insulin therapy while oral antidiabetic agents and/ or insulin (at a later stage) can be used in type-2 diabetes. Despite this vast armamentarium, it is not always possible to maintain glycemic control close to normal. ${ }^{[1]}$ The presently available drugs have limiting adverse drug reactions (ADRs) like hypoglycemia and weight gain (with sulfonylureas, thiazolidinediones), lactic acidosis (with biguanides) and edema (with thiazolidinediones), in addition to restrictions for use in organ dysfunction. UKPDS has shown that B-cell failure is progressive despite therapy with insulin, sulfonylureas and biguanides. No current therapy can slow this decline in patients with type-2 diabetes. ${ }^{[3]}$ Hence an ideal antidiabetic agent should delay/arrest, if not reverse the cell decline which can be used synergistically with current therapies with no added adverse drug reaction profile or serious adverse drug reactions, thus reducing long term complications and hence morbidity and mortality.

To help these patients further, a new class of agents: Incretin mimetics has been developed. Zung and La Barre proposed the term "incretin" referring to insulin stimulating hypoglycemic factor found in the extract of duodenum. Hence incretin hormones are the hormones produced by the gastrointestinal tract in response to nutrient entry resulting in stimulation of insulin secretion (insulinotropism). Glucagon like peptide-1 (GLP-1) and gastric inhibitory polypeptide (GIP) are two such examples. Gut insulinotropic agents like GLP-1 are secreted by enteroendocrine L-cells of gastrointestinal tract (duodenum, jejunum, ileum and colon) in response to food. ${ }^{[4]}$ Therefore an incretin dysfunction (release/action) would result in significant post-prandial hyperglycemia as manifested in impaired glucose tolerance and type-2 diabetes mellitus.

GLP-1 is reduced in obese, insulin resistant Type 2 diabetes mellitus patients. Standard meal tests in patients with type 2 diabetes have decreased GLP-1 responses and decreased insulin secretion as compared to non-diabetics. These lower GLP-1 levels are thought to be due to impaired secretion and decreased response rather than increased degradation/elimination of GLP-1. ${ }^{[5]}$

On subcutaneous administration, incretin-mimetics have proven to be effective in controlling hyperglycemia in patients with type 2 diabetes mellitus. ${ }^{61}$ Incretin mimetics enhance glucose dependent insulin secretion and other effects, net result of which is fall in raised plasma glucose levels.

\section{Chemistry}

Exendin-4 and Exendin-3 are the peptides isolated from the oral secretions of the Gila monster lizard (Heloderma suspectum). Both these peptides differ only in amino acid sequence at position 2 and $3 .^{[7]}$ Exendin-4 is a peptide hormone containing 39 amino acids. Exenatide is synthetic Exendin-4 and is now available commercially for use. Exenatide has a 53\% overlap in the amino acid sequences for that of naturally occurring human hormone GLP-1.

\section{Mechanism of action and pharmacodynamics}

It activates mammalian receptors for truncated glucagon like peptide-1 (tGLP-1) with a relatively prolonged action. ${ }^{[8]}$ This is due to absence of alanine at position 2, which is recognized by dipeptidyl peptidase (DPP) IV and hence becomes inherently resistant to cleavage by DPP. ${ }^{[6]}$ GLP-1 receptors are present in brain and pancreas and are coupled positively with adenylyl cyclase system. Ligand activation of $\mathrm{G}_{\mathrm{s}}$-linked GLP-1 receptor stimulates adenylyl cyclase thereby increasing intracellular C-AMP in a pulsatile manner in PC12 cells. ${ }^{[9]}$ Exenatide is 100 times more potent than GLP-1. ${ }^{99]}$ Hence it possesses insulinotropic properties similar to the activity of GLP-1.

This drug has multiple mechanisms of action, the net result of which is better glycemic control. The effects can be grouped as acute (immediate) effects: namely glucose dependent insulin secretion, suppression of post-prandial high glucagon levels, delayed gastric emptying and delayed (late) effects: weight loss, improved beta cell mass and function.

The most striking feature of this drug is glucose dependent insulin secretion, meaning that it stimulates insulin secretion mainly in the post-prandial period. This ensures a relatively lesser risk of hypoglycemia, as insulin secretion reduces with the fall in blood sugar level.

In addition, it decreases the post-prandial glucagon secretion that further augments its antidiabetic effect by decreasing hepatic glucose production and insulin requirements. It does not impair normal glucagon response to hypoglycemia (when needed). ${ }^{[10]}$ Additionally, it slows gastric 
emptying, thereby modulating absorption of carbohydrates into the blood stream. It probably changes hepatic versus peripheral partitioning of glucose metabolism. ${ }^{\mid{ }^{\mid l}}$ Thus, it controls glucose excursion in fed state.

It also leads to a feeling of satiety and fullness, resulting in decreased appetite, which may manifest as loss of weight. It also reduces post-prandial triglyceride levels.

At the cellular level, it promotes the differentiation of pancreatic progenitor cells into B-cells and improves their life span and function as well both by stimulating their

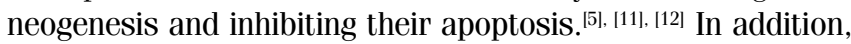
it promotes nerve growth factor (NGF) initiated differentiation and may rescue degenerating neurons after NGF- mediated withdrawal. ${ }^{[9]}$

\section{Pharmacokinetics}

Exenatide, being a peptide, needs to be administered parenterally and a dose of $10 \mathrm{mg}$ achieves a maximum concentration $\left(\mathrm{C}_{\max }\right)$ of $211 \mathrm{pg} / \mathrm{ml}$ in 2.1 hours $\left(\mathrm{t}_{\max }\right)$ along with mean area under the curve (AUC) of $1036 \mathrm{pg} * \mathrm{~h} / \mathrm{ml}$. The mean apparent volume of distribution is $28.3 \mathrm{~L}$. The drug is eliminated by glomerular filtration, followed by proteolysis. It has a clearance of $9.1 \mathrm{~L} / \mathrm{h}$ and mean terminal half life $\left(\mathrm{t}_{1 / 2}\right)$ of $2.4 \mathrm{~h}$. It requires dose adjustment only in severe renal failure (end stage renal disease) where the clearance reduces to less than $1 \mathrm{~L} / \mathrm{h}$, but no modification is required for mild to moderate renal failure. ${ }^{[13]}$

\section{Adverse effects}

Adverse drug reactions are few and mild to moderate in severity. These include: central nervous system (CNS) ADRs like dizziness, jitteriness, headache, uneasiness; gastrointestinal (GI) ADRs like nausea, vomiting, diarrhea, dyspepsia and a decrease in appetite; metabolic ADRs like hypoglycemia mainly when combined with a sulfonylurea; increased sweating and immunogenic reactions at the injection site. Gradual dose escalation minimizes doselimiting GI adverse events like nausea and vomiting without loss of glucoregulatory activity. ${ }^{[14]}$, ${ }^{115]}$ In one study, doses up to ten times the recommended doses were accidentally administered in three of the study subjects leading to severe hypoglycemia requiring parenteral glucose administration. The recovery in all the three cases was uneventful. ${ }^{[16]}$

\section{Drug interactions}

In view of delayed gastric emptying, a caution is required when exenatide is co-administered with certain drugs like paracetamol, digoxin, lisinopril, lovastatin, antiinfectives and oral contraceptives. It is advisable to administer these drugs at least one hour before the administration of exenatide with a light meal or snack (if needed).

\section{Contraindications}

It is important to remember that it is not indicated in diabetes mellitus type1 or diabetic ketoacidosis and that it is not an insulin substitute. It is not recommended for diabetics with end stage renal disease (creatinine clearance $<30 \mathrm{ml} /$ min) and severe gastrointestinal disease (like gastroparesis). It is yet to be studied in pregnant or lactating mothers.

\section{Special precautions}

It needs to be refrigerated at a temperature of $2-8^{\circ} \mathrm{C}$, taking care that it is not frozen. It also needs protection from light. ${ }^{[13]}$

\section{Clinical trials}

Buse et al. ${ }^{[17]}$ studied 377 patients having diabetes mellitus type-2 with inadequate glycemic control on maximally effective doses of sulfonylureas (monotherapy) over 30 weeks period in a randomized triple blind, placebo control study. The $\mathrm{HbA}_{1 \mathrm{C}}$ was reduced to less than $7 \%$ in $41 \%$ patients on 10 $\mathrm{mg}$ subcutaneous (s.c) twice a day and $33 \%$ on $5 \mathrm{mg}$ s.c twice a day $(\mathrm{P}<0.001)$. In addition, there was statistically significant weight loss $(\mathrm{P}<0.05)$. in the $10 \mathrm{mg}$ twice-daily arm of the study as compared to the placebo.

Fineman et al. conducted a randomized, double arm, triple blind, multicentric study enrolling 123 subjects who were given exenatide in gradually escalating doses starting at 0.02 $\mathrm{mg} / \mathrm{kg}$ thrice a day, increasing $0.02 \mathrm{mg} / \mathrm{kg}$ per dose every three days for 35 days. This mode of administration minimized dose limiting nausea and vomiting $(\mathrm{P}<0.001)$ with no loss of glucoregulatory activity. ${ }^{[14]}$

In another placebo controlled, blind study Fineman et al. enrolled 109 patients with inadequate diabetes control on dietary control or oral hypoglycemic agents (sulfonylureas or metformin) achieved $-\mathrm{HbA}_{1 \mathrm{C}}$ less than $7 \%$ in $15 \%$ of patients as compared to only $4 \%$ in the placebo group $(\mathrm{P}<0.006) .^{[18]}$

In a study conducted by Egan $e t$ al. with 10 patients having type-2 diabetes mellitus (insulin naïve), $\mathrm{HbA}_{1 \mathrm{C}}$ improved $(\mathrm{P}<0.009)$ after one month of treatment with once a day or twice a day bolus s/c injections. Maximum decline was seen in capillary blood glucose levels done before going to bed $(\mathrm{P}<0.001){ }^{[6]}$

\section{Use and approved indication}

FDA has approved this drug on April 30, 2005 for type-2 diabetes mellitus as an adjunct to metformin or sulfonylureas in the dose of $5 \mu \mathrm{g}$ subcutaneously twice a day within sixty minutes each of morning and evening meals.

\section{Advantages and disadvantages}

The advantages of this group of agents are:

1. Help to achieve better glycemic control in type-2 diabetics who are not well controlled with oral agents like metformin and/or sulfonylureas.

2. Decrease postprandial triglyceride levels and hence decrease the risk of ischemic heart disease.

3. Decrease appetite.

4. Cause weight loss.

Disadvantages of this group of drugs are:

1. Only parenteral route of administration (s.c)

2. Expensive

3. Risk of hypoglycemia increases, especially if given along with sulfonylureas.

\section{Future trends}

Studies are going on to prepare once a month injectable formulation of exenatide. ${ }^{|7|}$ Other longer acting GLP-1 analogs with high binging to albumin are under phase 2 clinical trials. 
In view of weight loss being observed with the use of this agent, research is going on to use it in patients with obesity. ${ }^{[19]}$ It may also have a role to play along with insulin in C-peptide negative type 1 diabetes mellitus. ${ }^{[15]}$ Incretin mimetic agents appear to be an important class of agents targeting the physiological defect other than insulin that has not been targeted earlier. These agents augment diabetic control and can easily be combined with other antidiabetic agents. Hence incretin mimetics are better suited for therapy in patients with diabetes.

In addition to glycemic control, it may be used to reverse or halt neurodegenerative process observed in diseases like peripheral neuropathy associated with type 2 diabetes, Alzheimer's and Parkinson's disease.

\section{S. Kaushal, S.C. Chopra, S. Arora \\ Department of Pharmacology,}

Dayanand Medical College and Hospital, Ludhiana141 001. Punjab E-mail: skaushal@yahoo.co.in

\section{References}

1. Silverstein J, Klingensmith G, Copeland K, Plotnick L, Kaufman F, Laffel L, et al. Care of children and adolescents with type 1 diabetes: A statement of the American Diabetes Association (ADA Statement). Diabetes Care. 2005;28:186-212, Silverstein J Care of children and adolescents with type1 diabetes. Diabetes Care 2005;28:186-212.

2. Powers AC. Diabetes mellitus. In: Kasper DL, Braunwald E, Fauci AS, Hauser SL, Longo BL, Jameson JL, editors. Harrison's Principles of Internal Medicine. Vol 2. $16^{\text {th }}$ ed. New York: McGraw Hill. 2005. p 2152-80.

3. Kolterman OG, Buse JB, Fineman MS, Gaines E, Heintz S, Bicsac TA, et al. Synthetic Exendin-4 (exenatide) significantly reduces post prandial and fasting plasma glucose in subjects with type-2 diabetes. J Clin Endocrinol Metab 2003;88:3082-9.

4. Perry T, Haughey N J, Mattson MP, Egan JM, Greig NH. Protection and reversal of excitotoxic neuronal damage by glucagon-like peptide 1 and exendin-4. J Pharmacol Exp Ther 2002;302:881-8.
5. Bloomgarden ZT. Gut- derived incretin hormones and new therapeutic approaches. Diabetes Care 2004;27:2554-9.

6. Egan JM, Meneilly GS and Elahi D. Effects of 1 mo bolus subcutaneous administration of exendin-4 in type 2 diabetes. Am J Physiol Endocrinol Metab 2003;284:1072-9.

7. Exenatide: AC2993, AC002993, AC2993A, Exendin-4, LY2148568. Drugs RD 2004;5;35-40.

8. Dupre J, Behme MT, McDonald TJ. Exendin-4 normalized postcibal glycemic excursions in type 1 diabetes. J Clin Endocrinol Metab 2004;89: 3469-73.

9. Degn KB, Brock B, Juhl CB, Djurhuus CB, Grubert J, Kim D, et al. Effect of intravenous infusion of exenatide (synthetic exendin-4) on glucose dependent insulin secretion and counter regulation during hypoglycemia. Diabetes, 2004; 53: 2397-403

10. Nauck MA, Meier JJ. Glucagon like peptide 1 \& its derivatives in the treatment of diabetes. Regu Pept 2005;128:135-48.

11. Joy SV, Rodgers PT, Scates AC. Incretin mimetics as emerging treatment for type 2 diabetes. Ann Pharmocother 2005;39:110-8.

12. Perry T, Lahiri DK, Chen D, Zhou J, Shaw KTY, Egan JM, et al. A novel neurotrophic property of glucagon -like peptide 1; a promoter of nerve growth factor-mediated differentiation in PC12 cells. J Pharmacol Exp Ther 2002;300:958-66

13. Antidiabetic agents, incretin mimetic agents. Exenatide. Drug facts and comparison 2005.

14. Fineman MS, Shen LZ, Taylor K, Kim DD, Barn AD. Effectiveness of progressive dose escalation of exenatide (exendine-4) in reducing dose limiting side effects in subjects with type 2 diabetes. Diabetes Metab Res Rev 2004;20:411-7.

15. Nielsen LL and Baron AD. Pharmacology of exenatide (synthetic exendin4) for the treatment of type 2 diabetes. Curr Opin Investig Drugs 2003;4: 401-5.

16. Calara F, Taylor K, Han J, Zabala E, Caee EM, Wintle M, et al. A randomized, open label, cross over study examining the effect of injection site on bioavailability of exenatide. Clin Ther 2005;27:210-5.

17. Buse JB, Henry RR, Han J, Kim DD, Fineman MS, Baron AD. Effects of exenatide (exendin-4) on glycemic control over 30 weeks in sulfonylurea - treated patients with type 2 diabetes. Diabetes Care 2004:27:2628-35.

18. Fineman MS, Bicsak TA, Shen LZ, Taylor K, Gaines E, Varns A, et al. Effect on glycemic control of exenatide (synthetic exendin-4) additive to existing metformin and/or sulfonylurea treatment in patients with type 2 diabetes. Diabetes Care 2003;26:2370-7.

19. Kastin AJ, Aakerstrom V. Entry of exendin-4 into brain is rapid but may be limited at high doses. Int J Obes Relat Metab Disord 2003;27:313-8.

\section{Free}

\section{Pharmacology Resource Material, Software \& Documents} available at 